\title{
Notas de Leitura
}

SOUZA, Donaldo B. de, FARIA, Lia

C.M. de., (orgs.). Desafios da educação municipal. Rio de Janeiro: DP\&A, 2003, 480p.

O livro é oriundo de projeto de pesquisa voltado para as reformulações da educação municipal ocorridas após a aprovação das novas Diretrizes e Bases da Educação Nacional, Lei no 9.394/96, desenvolvido no Núcleo de Estudos em Políticas de Educação (NUEPE) da Faculdade de Educação da Universidade do Estado do Rio de Janeiro (UERJ).

Os 20 ensaios escritos por 29 pesquisadores-especialistas têm como objetivo principal realizar uma análise crítica a respeito da nova $\mathrm{LDB}$, com dois focos: de um lado, financiamento e gestão de ensino; de outro, níveis e modalidades da educação municipal.

Pedro Demo, como apresentador da obra, acentua a importância das discussões trazidas pelos autores, no que concerne aos impactos e aos desafios postos pela LDB aos sistemas públicos municipais de educação. Por sua vez, os organizadores iniciam a coletânea com o prefácio A educação municipal pós-LDB: políticas de financiamento e gestão, que apresenta e contextualiza o conjunto de textos reunidos no livro.

Abordando 17 temas, a obra se estrutura em três partes. A Parte I-
Enfoque político-institucional em torno do financiamento e gestão do ensino, é composta por sete artigos, a saber: Estado, planejamento e democratização da educação, José Clovis de Azevedo; Conselhos Municipais de Educação: criação e implantação em face das novas atribuições dos sistemas municipais de ensino, Maria Celi Chaves Vasconcelos; Formulação dos planos de cargos e salários e estatutos do magistério: a nova legislação, Bertha de Borja Reis do Valle; Gestão financeira da educação: o legal $x$ o real? Nicholas Davies; Políticas federais de apoio: as tortuosas ruas de mão dupla das relações intergovernamentais, Candido Alberto Gomes, Beatrice Laura Carnielli e Myriam Christiano Maia Gonçalves; Avaliação da educação: novos desafios em contexto de municipalização, Alicia Bonamino e Creso Franco; e Participação popular: a escola como alvo do terceiro setor, Adolfo Ignacio Calderón e Vlademir Marim.

\section{A Parte II - Enfoque político-} educacional em torno dos níveis e modalidades de ensino, é constituída por outros dez artigos: A integração da educação infantil ao sistema de ensino: exigências e possibilidades pós-LDB, Vera Maria Ramos de Vasconcellos, Ligia Maria Leão de Aquino e Ana Paula Santos Lima Lanter Lobo; A universalização do ensino fundamental: o papel político-social da escola e o desafio das novas políticas de alfabetização e letramento, Cecília Maria Aldigueri Goulart; Formação de profissionais da educação infantil: um desafio para as políticas municipais de educação face às exigências da LDB, Patrícia Corsino, Maria Fernanda Nunes e Sonia Kramer; Políticas de formação de professores: quais os limites e possibilidades abertos pela LDB para as séries iniciais do ensino fundamental brasileiro? Célia Linhares e Waldeck Carneiro da Silva; Avanços e retrocessos: refletindo sobre a educação de jovens e adultos na década de 1990, Sandra Sales; Educação Profissional: iniciativas no âmbito dos sistemas municipais de ensino e suas possíveis relações no desenvolvimento de políticas de geração de trabalho e renda, Neise Deluiz e Marise N.

Ramos; Reformas educacionais pósLDB: a inclusão do aluno com necessidades especiais no contexto da municipalização, Júlio Romero Ferreira e Rosana Glat; A questão política do direito à educação da população do campo, Yolanda Lima Lobo e Roberto Faria; Mainói e Axi já: esboço do mapa da educação indígena no Rio de Janeiro, José Ribamar Bessa Freire; e Educação a distância: entre a legislação e a realidade, Raquel Villardi.

Na Parte III - Balanço dos limites e possibilidades da municipalização da educação pós-LDB, o livro apresenta dois estudos de caráter mais conclusi- 
vos, visando apontar limites e possibilidades da municipalização da educação brasileira, nos tempos atuais: Governo FHC: "Toda criança na escola?" quando $1+1$ é mais do que $2 \ldots$ nas estatísticas oficiais! Nicholas Davies; e Limites e possibilidades da educação municipal pós-LDB, Donaldo Bello de Souza e Lia Ciomar Macedo de Faria.

Desafios da educação municipal é uma obra de relevância para os professores e pesquisadores de políticas públicas em educação, dada sua postura teórica politizada e contemporânea. Os enfoques abordados salientam a necessidade de cumprimento dos mecanismos legais previstos nas leis e normas, assim como uma reavaliação das contradições e fragilidades da mesma. Nesse sentido, salienta que é preciso indagar acerca das políticas municipais para o campo educacional, cujas atribuições e responsabilidades carecem de tratamento equânime, assim como uma efetiva redistribuição de poder pelo conjunto de entes federados: União, estados e municípios.

\section{Débora Barreiros}

Mestre em Educação pela UERJ Professora substituta na Faculdade de Educação da UERJ

E-mail:dbarreiros@uol.com.br

LOPES, Alice Casimiro, MACEDO,

Elizabeth (orgs.). Currículo de ciências em debate. Campinas: Papirus, 2004, 192p.

Como entender, historicamente, as invenções e reinvenções curriculares voltadas para o ensino de Ciências que são propostas pelas instâncias educacionais oficiais diante dos desafios do mundo contemporâneo e da comunidade escolar na qual a escola se insere? Para discutir questões como essas, Currículo de ciências em debate, apoiando-se na produção teórica do campo do currículo, convida o leitor a compreender os sentidos das propostas curriculares para a área de Ciências, bem como a fazer leituras criteriosas acerca das muitas práticas e opções curriculares em Ciências que se colocam no interior da escola.

Organizada por Alice Casimiro Lopes e Elizabeth Macedo, a obra constitui-se em importante referência para os educadores de Ciências que desejam ampliar seus conhecimentos e suas reflexões teóricas a respeito do currículo das disciplinas Ciências Naturais, no ensino fundamental, e Biologia, Física ou Química, no ensino médio. Oferece significativos elementos para a compreensão de muitos questionamentos acerca do ensino das Ciências e permite maior aproximação entre essa área e estudos educacionais mais amplos. A problemática do currículo de Ciências recebe cuidadoso exame teórico por parte de suas organizadoras, bem como dos demais três autores, que abordam temáticas que também são parte das inquietações atuais de muitos professores e educadores. Assim, consegue interessar e instigar leitores que atuam em diferentes ambientes educacionais, ampliando as possibilidades de entender criticamente essas questões.

Os cinco capítulos do livro compõem-se de material analítico desenvolvido por seus autores e explicitam diversas perspectivas teóricas que subjazem às pesquisas por eles realizadas. Em toda a obra, currículo é entendido para além de um arranjo linearizado e ordenado dos conteúdos escolares e, ao se definir de forma distinta a essa, os autores focalizam, a partir de diferentes olhares e objetos, as questões culturais, políticas e sociais subjacentes ao currículo de Ciências.

O livro inicia-se com o ensaio de Attico Chassot, no qual são analisadas algumas dimensões históricas de abordagens científicas e tecnológicas que se fizeram presentes no ensino de ciências na segunda metade do século XX.

Chassot focaliza em particular projetos e iniciativas públicas para induzir um ensino experimental nas aulas das Ciências, bem como discute os projetos curriculares que foram importados dos Estados Unidos e da Inglaterra, na década de 1960. Contextualiza historicamente essas iniciativas no âmbito dos cursos de licenciatura das áreas científicas, localizando-as no conturbado cenário político da ditadura militar brasileira.

Alice Lopes discorre sobre as diferenças na interpretação do discurso dos Parâmetros Curriculares Nacionais do Ensino Médio (PCNEM) pelas disciplinas científicas da área das Ciências da Natureza, Matemática e suas tecnologias, centralizando sua análise nos princípios norteadores desse texto curricular, especialmente nos que dizem respeito aos conceitos de competências, interdisciplinaridade, contextualização e tecnologias, "idéias centrais dos PCNEMs que permanecem como marcas da reforma do ensino médio" (p. 53). A opção teórica utilizada por Alice Lopes ao examinar tais questões é particularmente instigadora porque, ao destacar o hibridismo associado às propostas curriculares no texto dos PCNEM, nelas reconhece políticas culturais. Conforme aponta, nesses textos evidencia-se "o hibridismo intrínseco à recontextualização de políticas curriculares" (p. 48). Com base nessa análise, é possível pensar que esse caráter híbrido tem confundido e aprisionado muitos leitores, levando-os a reconhecer em tais textos fragmentos de abordagens com as quais concordam, desconsiderando as contradições na concepção de currículo subjacente a esses textos.

Com Elisabeth Macedo encontramos uma análise dos currículos de ensino de Ciências do Rio de Janeiro, na qual ressalta o valor político dos estudos culturais por permitir "a articula- 